\title{
Practice Exploration on the Folk Performing Art Higher Education Zhou Zhuang
}

Folk Performing Art Department of Arts College in University of Science and Technology LiaoNing, Anshan, Liaoning, China

413951948@163.com

Key words: New era, higher education, folk performing art.

\begin{abstract}
Since the reform and opening-up, Chinese higher education has developed rapidly and a variety of subjects are booming. Chinese education career is showing leap-type development. As a vital part in Chinese traditional culture, folk performing art is at the priority status for telling Chinese story. It carries thousands of spiritual civilization of Chinese nation, witnessing development history and writing down the great rejuvenation poem. With era importance, the higher education of folk performing art undertakes dual missions for enriching the higher education discipline system and inheriting \& developing Chinese excellent traditional culture. It is the solid foundation for Chinese traditional culture to achieve full inheritance and development, which existence has an important era meaning.
\end{abstract}

\section{曲艺高等教育的实践探究}

\author{
周壮 \\ 艺术学院曲艺系, 辽宁科技大学, 鞍山, 辽宁, 中国 \\ 413951948@163.com
}

关键词：新时代; 高等教育; 曲艺

摘要. 改革开放以来, 中国高等教育事业振兴腾飞、蓬勃发展, 各类学科百花齐放、百家争 鸣, 中国教育事业呈现跨越式发展。而曲艺是中国优秀传统文化当中不可缺少的重要组成部 分, 讲好中国故事, 曲艺必先行, 这门艺术承载着中华民族几千年的精神文明, 见证着中华 民族历尽沧桑的䇢路蓝缕, 谱写着中华民族伟大复兴的壮美诗篇。曲艺高等教育担负着丰富 中国高等教育学科体系与传承发展中华优秀传统文化的双重使命, 是使一脉相承的中国优秀 传统文化得到充分继承和发展的坚实基础, 其存在具有十分重要的时代意义。

\section{1. 引言}

曲艺作为一门古老的艺术，博大精深、源远流长，其 “可证之史短，可溯之源长”。最 早与曲艺相关的历史可以追溯到春秋战国时代的 “优伶”，其身份便是在诸侯国国君身边供 王公贵族享乐的表演艺人。如司马迁在《史记 - 滑稽列传》中记载的楚庄王熊吕时期的优孟, 秦始皇贏政时期的优斿等, 都是历史上比较出名的艺人。

曲艺在各个历史时期都以不同的表现形式和艺术手法不断存在并繁衍着。如唐代的俗讲、 大曲、参军戏, 宋代的说话伎艺、鼓子词、诸宫调, 以及明、清至民国时期的道情、莲花落、 凤阳花鼓等艺术形式, 都包含着鲜明的曲艺灵活多样、贴近老百姓生活的特点。它们之间既 
各具特色, 却又一脉相承, 这充分体现了曲艺作为中华优秀传统文化的一支重要血脉所具有 的鲜活生命力和时代感召力。

作为中华优秀传统文化的组成部分需要不断的传承与发展。曲艺本来就是一种属于中华 民族自身的文化财富, 它不是舶来品, 而是长期根植在广大人民群众当中, 我们本土 “土生 土长” 的自己的艺术形式, 它具有从群众中来、到群众中去的特点, 是广大人民群众喜闻乐 见的一种艺术形式。曲艺与曲艺高等教育之间的关系如同科研成果与课堂, 科研人员想要传 播学术成果, 就必须通过课堂使广大知识分子了解理论的实质与核心; 曲艺要想真正的使人 们了解其内涵和特点, 就必须总结客观规律, 并通过曲艺高等教育这间大课堂上升一个层次, 提升本土化艺术的地位, 让更多青年朋友了解、熟知这门艺术, 领悟其独特的美丽与真谛, 并投身于表演和教育之中, 曲艺高等教育既是培养高素质曲艺人才的有效途径, 也是向广大 人群民众传播扩散的重要渠道。

\section{2. 增强中华民族凝聚力和文化自信心的重要手段}

提升曲艺艺术的地位就是提升中华民族的文化自信，本土的艺术形式得不到发扬，何谈 自信, 曲艺艺术是有灵魂的, 它的魂是构筑在中华大地五千年文明历史之中的民族之魂。曲 艺代表的不仅仅是一门艺术形式, 它的社会价值在于使中华几千年优秀传统文化的得到了充 分的继承与发展，它的历史价值在于证明了中华历史千百年来的文化积淀，它的最终价值在 于为增强中华民族的凝聚力和自信心贡献了磅礴力量。

曲艺在任何历史时期都是中华民族的至臻瑰宝。每当中国社会繁盛时期，总会有曲艺作 品讴歌和赞许广大劳动人民的美好生活; 但逢国家处于为患之际, 总能够涌现出一大批爱国 曲艺工作者奔走呼号、救亡图存。例如已故的相声大师常宝勍（小蘑菇）先生在抗日战争时 期创作的相声《牙粉袋》，它就是通过相声的表演揭露日本侵略者的对我中国人民的残酷压 迫与剥削, 针砭时弊, 借此唤醒广大的劳苦大众团结起来, 一致抗战。新中国成立后, 常宝 壁先生在抗美援朝战争中壮烈牺牲。

一批批优秀的曲艺工作者为实现中华民族的独立与自强前赴后继、奋不顾身，体现了革 命的牺牲精神和大无畏精神, 用鲜血与生命谱写了一曲曲华丽又神圣的壮美乐章。不过, 这 些不畏艰险、不怕牺牲的优秀曲艺人才不是凭空出现的, 不是天生自在的产物, 而是需要挖 掘, 需要时间和实践培养的, 曲艺高等教育的重要意义就在于此。

曲艺高等教育的核心问题在于为谁培养人，培养什么样的人和怎样培养人。从历史唯物 主义角度出发, 我们可以辩证的分析出: 曲艺高等教育是为中国特色社会主义事业培养新时 代曲艺工作者; 曲艺高等教育要培养德、智、体全面发展的中国特色社会主义事业的曲艺高 等人才; 曲艺高等教育教学培养过程必须坚持马克思主义的基本原理并于自身实践相结合, 坚持理论联系实际, 坚持历史唯物主义和辩证唯物主义的观点, 培养一大批能够提升中华民 族文化自信心、凝聚力和讴歌新时代、新风貌, 弘扬社会正能量的表演、创作高等人才。

\section{3. 弘扬社会主义核心价值观的有效途径}

任何一个社会都存在多种多样的价值观念和价值取向, 要把全社会意志和力量凝聚起来, 必须有一套与经济基础和政治制度相适应并能形成广泛社会共识的核心价值观。核心价值观 在一定社会的文化中是起中轴作用的, 是决定文化性质和方向的最深层次要素, 是一个国家 的重要稳定器。习近平总书记指出: “人类社会发展的历史表明, 对一个民族、一个国家来 说, 最持久、最深层的力量是全社会共同认可的核心价值观。” 如果没有共同的核心价值观, 一个民族、一个国家就会魂无定所、行无依归。 


\section{1 立足中华优秀传统文化}

牢固的核心价值观，都有其固有的根本。中华文明绵延数千年，有其独特的价值体系。 中华优秀传统文化已经成为中华民族的基因，植根在中国人内心，潜移默化影响着中国人的 思想方式和行为方式。提倡和弘扬社会主义核心价值观，必须从中汲取丰富营养，否则就不 会有生命力和影响力。要利用好中华优秀传统文化蕴含的丰富思想道德资源, 使其成为涵养 社会主义核心价值观的重要源泉。

\section{2 与践行社会主义核心价值观紧密结合}

社会主义核心价值观是中国特色社会主义精神文明建设的重大课题。曲艺高等教育作为 承启中国优秀传统文化的实质载体, 在弘扬社会主义核心价值观的伟大实践中具有十分重要 的地位和意义。早在长征时期, 红军宣传队工作人员就通过曲艺当中的快板向群众宣传党的 路线、方针、政策和理论思想，为日后完成新民主主义革命、建立新中国夯实了群众與论基 础。

曲艺艺术如同播种机，把革命种子酒向了全国各地。新的历史时期，曲艺高等教育同样 担负着宣传党的路线、方针、政策和理论思想，宣传社会主义核心价值观的重要任务。曲艺 高等教育不仅要培养优秀的曲艺人才, 还要使这些优秀人才发挥自身所长, 为弘扬社会主义 核心价值观贡献力量, 加中国特色社会主义精神文明建设, 为实现 “五位一体” 总体布局打 下良好基础。

\section{4. 加快完善曲艺高等教育学科体系}

2004年之前，在全国各大艺术门类中，惟独曲艺在高校中还没有开设过本科专业，甚至 高等学校的学科目录中都没有曲艺这个专业, 是一个空白, 就算至今国曲艺本科专业的数量 也只是个位数。

辽宁科技大学艺术学院2004年作为全国首例, 创办了国内第一个本科层次的曲艺专业, 开创了本科曲艺高等教育的先河。创办曲艺专业, 不仅可以形成我国高等学校的一大特色, 同时可以使曲艺这门代表中华优秀传统文化的艺术得到更好地传承和发展。

不过，在高校中创办曲艺本科专业，既没有多少可供借鉴的成功历史经验，又缺少系统 的教材, 更为关键的是, 即便专业办起来了, 师资、学生就业及可持续发展等面临的一系列 问题接踵而至，不容忽视。

如何使曲艺学科在浩瀚如海的学术体系当中生根发芽是我们全体曲艺高等曲艺教育工作 者最为迫切、最亟待解决的重大课题。我们必须加快完善曲艺高等教育教学体系, 继续不断 深入曲艺高等教育的相关研究, 培养更多优秀曲艺高等人才, 把思想和行动都统一到振兴与 发展曲艺高等教育上来。

\section{1 曲艺高等教育不断培育和塑造符合新时代需要的曲艺人才}

辽宁科技大学艺术学院曲艺系作为全国第一所本科层次曲艺高等教育教学单位, 从2004 年至今已经培养了九届曲艺表演专业毕业生。这些优秀人才有的进入了专业演出团体, 有的 充实到部队、企业的宣传机构, 有的留校任教, 还有的进入了更高层次的学府继续深造。

不论他们身处什么岗位, 从事什么样的职业, 他们身上都具有曲艺所带给他们的独特优 点。“尊师重道” 教给学生做人的基本原则, “德才兼备” 培养学生综合的能力素养, “德 艺双馨” 赋予学生高尚的人格品质。在教学培养的过程当中, 学院一直强调人才培养目标的 外向型、复合型和应用型。培养 21 世纪社会主义现代化建设需要的, 德、智、体、美全面发 展的, 掌握并具备评书、相声、小品等喜剧表演艺术的基本理论和基本技巧的全能人才。

随着改革开放的不断深化，西方文化开始与我国传统文化不断产生交流与摩擦，许多传 统文化在这场变革中失去了原本光鲜亮丽的样子。我们与西方文化不断接触的同时, 需要坚 
持求同存异的方针, 不过我们自身几千年的传统文化也需要更多人才继承与弘扬。传统艺术 的发展离不开人，只有优秀的人才去继承，中华优秀传统文化才能彰显它绚丽的光彩。

在新的历史时期、新的形势下，我国对各类优秀人才的渴望比以往任何时候都要强烈, 我们应当倍加珍惜、始终坚持、不断发展。培养德、智、体全面发展的中国特色社会主义事 业的建设者和接班人是国家对高等教育事业的要求, 而培育德、智、体全面发展的中国特色 社会主义事业的优秀曲艺高等人才，既是时代的感召，也是曲艺在新时期新形势下新的历史 使命和义不容辞的责任。

\section{2 曲艺高等教育需要与时俱进}

曲艺高等教育需要与时俱进一一为实现中华民族伟大复兴的中国梦作出应有贡献。曲艺 是一门传统艺术，其艺术特点在保留自身特色的同时，必须与时俱进，摒弃脱离当前客观实 际的落后之处, 与当今社会紧密接轨, 做到取其精华, 去其糟粕, 推陈出新, 革故鼎新, 避 免同其他消亡的艺术形式一样，走入被湮没历史潮流之中的悲惨结局。

曲艺高等教育担负着培养和挖掘优秀曲艺高等人才的重要使命, 必须严格按照科学的教 育教学规律展开各项工作, 不能偏离时代这个宏观主题。在教学与授课过程当中要把曲艺当 中必须坚持理论与实践相结合、传统与现代相结合、先进成果与社会实际相结合。

“时势造英雄，英雄顺势时”。任何时期我们都不能违背社会历史的发展进程，不能偏 离社会前进的总方向。我们必须遵循历史唯物主义的客观规律, 坚持实事求是的工作方法, 始终践行群众路线的根本路线，做到只争朝夕、时不我待，把曲艺高等教育与实现中华民族 伟大复兴的中国梦紧密结合，培养出更多更精的新时期中国特色社会主义曲艺高等人才。

\section{5. 结论}

当下一个时期和阶段，正是决胜全面建成小康社会，实现第一个 “百年” 宏伟目标的关 键时期, 全国各行各业工作者都在夜以继日、风雨兼程。作为从事曲艺高等教育的一线教师, 我们更应当倍加珍惜、备受鼓舞, 决心大有一番作为, 加快曲艺高等教育教学体系建设完善, 不断推动曲艺高等教育事业向前迈进, 努力开创曲艺高等教育新局面, 为曲艺高等教育添砖 加瓦，为实现中华民族伟大复兴的中国梦作出应有贡献。

\section{References}

[1] Publicity Department of the CPC Central Committee, General Secretary Xi Jinping's Important Speech on the Literature and Art Forum, Learning Press, 23-28, 2015.

[2] Opinions of CPC Central Committee on Prosperity and Development of Socialism Literature and Art, People's Publishing House, 4-8,2015

[3] Dong Yaopeng, Chinese Folk Performing Art Booklist Overview, Higher Education Press, 26-30,2017 